\title{
LOS TOROS Y LA LEGISLACIÓN ESPAÑOLA. A PROPÓSITO DE LA SENTENCIA DEL TRIBUNAL SUPERIOR DE JUSTICIA DE CATALUÑA 854/2001, DE 11 DE JULIO *
}

Francisco Lara

Universidad de Granada

RESUMEN. A partir del análisis de una sentencia del Tribunal Superior de Cataluña y de las leyes españolas que prohíben el maltrato animal, el autor sostiene que no existen aceptables argumentos jurídicos, estéticos o éticos para defender, como se hace en dichas leyes, que los espectáculos taurinos sean considerados una excepción a tal prohibición.

Palabras clave: derechos de los animales, libertad creativa, ética aplicada.

ABSTRACT. From the analysis of a decision taken by the Superior Court of Catalonia and of the Spanish laws prohibiting animal mistreatment, the author maintains that there are not convincing legal, aesthetic or ethical arguments to defend that bullfighting could be considered an exception to that prohibition.

Keywords: animal rights, artistic liberty, applied ethics.

* Fecha de recepción: 11 de julio de 2010. Fecha de aceptación: 8 de septiembre de 2010. 


\section{RESUMEN DE LA SENTENCIA DEL TRIBUNAL SUPERIOR DE JUSTICIA DE CATALUÑA 854/2001, DE 11 DE JULIO}

1. Hechos: El Ayuntamiento de Barcelona, conocedor de que se va a proceder al rejoneo de un toro en el intermedio de la representación de la obra «Carmen, ópera andaluza de corneta y tambores» en la Plaza Monumental de Barcelona, programada el 15 de septiembre de 1999, insta a los organizadores del espectáculo a que no se proceda a dicho rejoneo por constituir éste un supuesto de vulneración de la Ley 3/1988, de 4 de marzo, de protección de animales. Los promotores del espectáculo reclaman ante los tribunales que esa decisión administrativa vulnera su derecho fundamental a la creación y producción artística reconocido en el art. 20.1.b) de la Constitución Española.

2. Fallo: El Tribunal Superior de Justicia de Cataluña estima el recurso de apelación interpuesto declarando la conculcación del derecho fundamental a la libertad de creación artística y reconociendo el derecho del recurrente a una indemnización.

3. Las razones del Tribunal: La no autorización del espectáculo en su totalidad es una vulneración de la libertad de creación y producción artística, puesto que el rejoneo se iba a practicar conforme a las reglas del toreo en una instalación que tiene ese fin. Las dos partes de las que consta el evento se ajustan a la norma vigente sobre espectáculos y, además, ha de tenerse en cuenta «... la amplia tolerancia de la sociedad en que iba a producirse la representación. Sirva de ejemplo la exposición de la artista británica Sarah Lucas en el Centre Cultura Tecla Sala de l'Hospitalet en la temporada 2000-2001 utilizando pollos empalados por tubos fluorescentes».

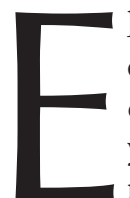

1 análisis de esta sentencia nos dará resultados muy distintos según la forma en que lo llevemos a cabo. Por un lado, podemos analizar la argumentación del Tribunal sobre la adecuación de los actos juzgados a la normativa vigente, y desde aquí, la sentencia no deja de ser, como veremos en la primera parte de mi trabajo, un ejemplo de falta de profesionalidad en algunos miembros de la judicatura española. Pero es posible también una segunda lectura de la sentencia que, yendo más allá del proceder del Tribunal, permita mostrar de manera manifiesta ciertas incongruencias importantes de nuestro ordenamiento jurídico. Esta última lectura es la que más me interesa aquí y la que desarrollaré a partir de la segunda sección. Con ella pretendo demostrar que la legislación a la que se refiere la sentencia, sobre el uso de animales en espectáculos públicos, se apoya en una justificación débil, producto tanto de un desesperado interés de nuestros legisladores por proteger los eventos taurinos como de una ilógica consideración de nuestra relación moral con los animales.

\section{UN EJEMPLO DE INCORRECTA APLICACIÓN DE LA LEY}

Tras un considerable esfuerzo de comprensión, motivado en parte por la pésima redacción de la sentencia, se pueden aventurar los dos argumentos que el Tribunal parece aducir para acabar dando la razón a los promotores del espectáculo no autorizado, que se quejan de una vulneración de su derecho fundamental a la creación artística.

El principal de esos argumentos para sostener que estamos ante un caso de censura consiste en intentar demostrar que se ha denegado el permiso para una representación que se ajusta a la legislación vigente, en concreto a la Ley de Cataluña, de 4 de marzo 
de 1988, sobre protección de animales. Pues aun cuando en el art. 4 de dicha ley se prohíba «el uso de animales en espectáculos, peleas y otras actividades, si ello puede ocasionarles sufrimiento o puedan ser objeto de burlas o tratamientos antinaturales, o bien si pueden herir la sensibilidad de las personas que los contemplen», se excluye de tal prohibición «la fiesta de los toros en aquellas localidades donde, en el momento de entrar en vigor la presente ley, existan plazas de toros construidas para celebrar dicha fiesta». Por tanto, concluye el Tribunal, no se puede prohibir la representación de la ópera aduciendo que ésta incluye un rejoneo, pues éste se celebraría, conforme a la citada ley, en una plaza de toros, la de Barcelona, construida para tal tipo de celebraciones, y con anterioridad a la promulgación de la ley.

La argumentación del Tribunal se completa finalmente con la observación de que, para los magistrados, en la sociedad barcelonesa se da una «amplia tolerancia» ante la utilización artística de animales. Y se señala, en su apoyo, la exposición que en 2000 realizó la británica Sarah Lucas en el centro cultural Tecla Sala de l'Hospitalet, en la que se utilizaban pollos empalados por tubos fluorescentes ${ }^{1}$.

Empezando por lo que considero más fácil, apuntaré dos razones para mostrar la debilidad de este segundo argumento del Tribunal. La primera es que los dos actos que se pretenden equiparar con la intención de demostrar que si uno no es grave el otro tampoco debería serlo, realmente no son equiparables. Pues un sufrimiento como el que se provoca con la lidia no forma parte de una exposición en la que sólo se muestran cadáveres de animales que, además, podrían haber perdido la vida de manera indolora.

Conviene señalar en segundo lugar que, aun cuando aceptáramos la pretendida equiparación de esos dos espectáculos, el argumento aún adolecería de la falacia de concluir una generalidad, la tolerancia de la sociedad barcelonesa hacia el uso cruel de los animales en el arte, a partir de un hecho particular, la inclusión en una exposición de una obra en la que ni siquiera se maltrata a animales, sólo se usan sus cadáveres, algo que, también con pretensiones artísticas o de divulgación científica, se viene haciendo en nuestro país con cadáveres humanos ${ }^{2}$. Y además, podría añadirse, si algo puede determinar con mayor rigor qué es lo que piensa la sociedad barcelonesa sobre este asunto, eso es la legislación que al respecto han elaborado sus representantes autonómicos; y en ésta, pionera en España en la protección de los animales, queda claro, como acabamos de ver, que a la sociedad catalana no quiere que se haga arte que conlleve menoscabo del bienestar animal.

A esta normativa autonómica sobre espectáculos es a lo que, vista la debilidad de su primer argumento, debe atenerse exclusivamente el Tribunal para establecer que

${ }^{1}$ El resto de la sentencia pretende, sobre todo, defender que la empresa encargada de explotar la representación de la obra, que es quien invoca en la denuncia la vulneración del derecho a la libre expresión artística, está legitimada para hacerlo, y que esto no es un privilegio exclusivo del autor. Hay otra parte de la sentencia que el Tribunal dedica a exponer una inconexa y superflua revisión de la jurisprudencia estatal y europea sobre libertad de expresión artística.

2 Como la exposición que, con el título Bodies, se exhibió, bajo la dirección de Roy Glover, a finales de 2007 en Barcelona. A través de 17 cadáveres y más de 200 órganos humanos reales, preservados con un sofisticado sistema de plastificado, el visitante podía conocer todos los detalles del cuerpo humano. Iba así en la línea de otras muchas exposiciones de este tipo, entre las que destacan las tituladas Mundos corporales, del famoso químico y médico alemán Gunther von Hagens. 
la Generalitat, con su denegación del permiso para representar la ópera «Carmen», atenta contra la libertad creativa de su autor y sus promotores. Es decir, ha de ceñirse a la demostración de que, en contra de lo mantenido por el gobierno catalán, la representación de la ópera cumple la Ley 3/1988, de 4 de marzo, de protección de animales. Y en esta tarea es clave para el Tribunal, y así lo entiende éste, que se pueda entender el evento en cuestión como una suma de dos espectáculos distintos: por un lado, la ópera, y por otro, la lidia que se celebraría en el intermedio de aquélla. Partiendo el espectáculo en dos se podría mantener que ambos, por separado, se ajustan a la legalidad. La ópera, porque en ella no se maltrata a ningún animal, y la lidia del intermedio, porque el arte del rejoneo se llevaría a cabo conforme a las reglas del toreo y en un lugar autorizado para ello, tal y como sexige la ley catalana. En cambio, si no se entendiera así el espectáculo, si lo concibiésemos como un todo en el que se integra el rejoneo, sí se estaría atentando claramente contra la citada ley. En tal caso, al presenciar el rejoneo nos encontraríamos no ante una manifestación de lidia convencional, sino ante una escena más de un espectáculo musical.

El problema radica, no obstante, en la dificultad de concebir el espectáculo como una suma de dos eventos independientes. Pues hay hechos que sólo se entienden si asumimos que la intención de los creadores y promotores era considerar la representación como un todo unitario, y nunca como un espectáculo, la ópera, que va acompañado de otro, consistente en el rejoneo de un toro y que sólo pretende entretener al público en el descanso. Por ejemplo, el mismo título completo de la obra: «Carmen, ópera andaluza de cornetas y tambores, según la leyenda primitiva contada por viejas cigarreras de Triana con incorporación de la lidia por rejoneo de un toro en medio de la ópera». Parece claro, por el título, que lo que el autor ha pretendido es representar la clásica obra del compositor francés Georges Bizet desde una perspectiva más andaluza, en la que se utilicen recursos escénicos tan autóctonos e impresionantes como las bandas de cornetas o la lidia de un toro. Ésta forma parte esencial entonces de la obra que se representa.

En esa misma dirección de ver el espectáculo como no fragmentable apunta también un segundo hecho: la manifestada negativa de los promotores a representar la ópera sin el rejoneo. Pues si realmente éste se presentara, tal y como se aduce, como una mera distracción para el intermedio, no debería preocupar tanto su supresión. Cuando, por el contrario, se rechaza absolutamente la posibilidad de representar la ópera sin el rejoneo es fácil pensar que, a pesar de lo que se diga en otro sentido, el autor y los promotores conciben el evento como un todo unitario del cual el rejoneo es una parte ineludible.

Precisamente es esta concepción de todo unitario la que defenderá dos años después en una sentencia sobre los mismos hechos (820/2003, de 16 de junio), contradiciéndose a sí misma, la Sección 2. ${ }^{a}$ de la Sala de lo Contencioso-Administrativo del Tribunal Superior de Justicia de Cataluña. En esta sentencia posterior el Tribunal desestima el recurso de apelación, interpuesto por la Delegación Territorial del Gobierno de Cataluña en Barcelona, en el que se aducía que mientras que el acto impugnado en sentencia firme ${ }^{3}$ había sido la no autorización de la representación de la ópera, ahora

3 Sentencia que se consideraba firme tras haber desestimado el Tribunal Supremo el recurso de casación en interés de Ley en su Sentencia 2003/2013, de la Sala de lo Contencioso-Administrativo, Sección 7. ${ }^{\text {, }}$, de 28 
debía enjuiciarse ese otro, basado en la resolución de aquella Delegación de 28 de junio de 2002, que autorizaba la celebración de aquel espectáculo «siempre y cuando no se llevase a término el rejoneo». De manera sorprendente, el Tribunal considera ahora que igualmente hay (de manera incluso «más gravemente lesiva») en esa autorización condicionada una vulneración del derecho a la libertad creativa porque «se obtendría así por la Administración el mismo resultado final: la no representación de la obra, al haberla desnaturalizado, al obligar a presentarla mutilada».

En definitiva, estamos ante una sentencia que por sus farragosas, falaces y contradictorias argumentaciones sólo podría ser merecedora de atención por constituir un ejemplo de pésima aplicación de la ley ${ }^{4}$. Pero, como decíamos más arriba, a mí la sentencia me resulta interesante por otros motivos. Sobre todo, porque refleja, más claramente si cabe, lo absurdo de una legislación, a la que remite, que se justifica como instrumento para impedir que públicamente se maltrate a animales y que, sin embargo, reconoce como excepción a la norma la celebración de muchos eventos públicos en los que, como parte de las fiestas, se somete a los toros a un extremo sufrimiento antes de acabar quitándoles la vida. La incongruencia de la ley se hace palpable en esta sentencia, cuando resulta que la legalidad del rejoneo depende sólo de si conseguimos o no considerarlo como parte accesoria de la ópera. Si lo conseguimos, el sufrimiento del toro es legal; si no, no lo es. Creo que una ley que permite esta desatinada línea de razonamiento de la sentencia, sin que se atente con ello contra el espíritu de la ley, debe ser una mala ley. Por tanto, el fallo de la sentencia reside no sólo en unos magistrados que aprovechan todos los resquicios de la ley para aplicarla en beneficio de las corridas sino también en unos legisladores que no se atreven a —o quizá no quieran- ser congruentes en sus decisiones. Esta incoherencia última de las leyes, que hace doblemente ridícula la sentencia que comento, es la que me interesa especialmente y a la que voy a dedicarme a continuación ${ }^{5}$.

de enero de 2003. El Tribunal Supremo desestima el recurso de casación interpuesto por la Generalitat de Cataluña porque básicamente «el debate (sobre si se conculca el derecho fundamental de libertad de creación) se concreta y circunscribe a un caso específico de un espectáculo, lo que ya de entrada supone la innecesariedad de una doctrina legal que impida en el futuro actuaciones similares, por no haber temor racional de que se reitere y aplique en casos de fácil repetición, con efecto multiplicador grave y con un extenso ámbito de generalidad, que es justamente lo que orienta tal clase de recurso de casación en interés de Ley».

${ }_{4}$ Mucho más dura en la valoración de la conclusión del Tribunal es la magistrada Nuria Clèries en su voto discrepante a esta sentencia — cuyas ideas principales repetirá en su también voto discrepante a la Sentencia del Tribunal Superior de Justicia de Cataluña núm. 820/2003, de 16 de junio-. Tras dar razones para creer que el acto que se juzga es unitario, añade que «no resulta factible que en el mismo concurran dos regulaciones diversas y contradictorias en cuanto a sus resultados, salvo que se admita una partición del espectáculo con el único objetivo de evitar la aplicación de la legislación vigente, y especialmente, la Ley 3/1988, de 4 de marzo, partición que, al tener como único motivo la evitación de la aplicación de la legislación vigente, debe considerarse como un fraude de ley».

5 Este enfoque más profundo también parece interesar a todos los participantes en el proceso que lleva a la sentencia que comento. Todos quieren resolver si dentro del marco jurídico español o comunitario no supondría una violación clara del derecho a la libertad creativa la prohibición de espectáculos en los que se maltrata a animales. Realmente esto no debería ser una cuestión relevante en el debate entre recurrentes, tribunal y magistrados discrepantes, pero lo es. Los que entienden que se conculca la libertad creativa no tendrían que hablar de censura ni desarrollar extensos argumentos sobre la necesidad de limitar lo menos posible dicho derecho. Deberían limitarse a considerar si los hechos contradicen o no la normativa vigente. Y en ese sentido, si el Tribunal dudara de la constitucionalidad de la legislación catalana sobre espectáculos, lo que debería hacer es desestimar el recurso contencioso-administrativo y proceder al planteamiento de cuestión de inconstitucionalidad ante el Tribunal Constitucional. Por otro lado, los que defienden el punto de vista de que no hay violación 


\section{2. ¿EL ARTE DE LOS TOROS?}

La cuestión clave que subyace a la legislación catalana sobre animales en lo tocante a la sentencia comentada es la de cuáles son los límites del derecho a la libertad creativa. Y se deriva de tal legislación que uno es libre para crear siempre y cuando ello no se plasme en un espectáculo donde se maltrata a animales. Sin embargo, se admite que los espectáculos taurinos son una excepción a esa regla. Esta excepcionalidad podría justificarse, en un principio, argumentando que en los espectáculos taurinos se manifiesta un tipo de arte tan indiscutible, digamos, que permite diferenciarlo claramente de otras posibles formas de hacer arte infligiendo sufrimiento a los animales.

Antes de entrar a analizar el fundamento y las limitaciones de la premisa general de que el arte no puede hacerse a costa del sufrimiento animal, quiero plantear no ya si el arte de la lidia es tan relevante y especial como para considerarlo una excepción a la regla, sino más básicamente si hay algo de arte en dicha práctica (y no, por supuesto, en otro tipo de espectáculos taurinos, como los encierros o suelta de reses, que ni los propios aficionados calificarían como manifestaciones artísticas).

Para tal objetivo voy a exponer los tres tipos de argumentos que he encontrado en la escasa y confusa literatura existente sobre el valor estético de las corridas.

En primer lugar, se ha dicho a veces que la lidia es arte en virtud de su carácter esencialmente lúdico; de consistir en una actividad que, por no ser necesaria para la subsistencia, sólo pretende la mera distracción, un factor esencial para poder dedicarse al juego de la creación ${ }^{6}$. Pero obviamente no toda diversión puede ser arte. Para que la distracción se convierta en creación artística debe darse algún otro criterio añadido, como, por ejemplo, el dominante en alguno de los dos siguientes argumentos.

Como aquel que sitúa lo artístico de las corridas en su potencialidad para expresar determinadas emociones que sólo captan los entendidos. Para PÉREZ DE AYALA, por ejemplo, el toreo es una diversión que se hace artística por la complejidad de las emociones que suscita, no las simples que estriban en presenciar el riesgo real de jugar con la muerte, que todo espectador puede percibir fácilmente, sino aquellas más complejas y ricas en asociaciones y elementos estilísticos o estéticos. Y en un poco esclarecedor párrafo, AyALA define esos elementos estéticos como consistentes en «sabor, gracia, qué sé yo; un quid divinum que hace que las corridas de toros, además de ser repugnantes, bárbaras y estúpidas, sean bellas» ${ }^{7}$.

En un intento por ser algo más esclarecedor, por descifrar ese «qué sé yo» al que se refería AYALA, el filósofo y ensayista P. CABA mantuvo que lo que se expresa en la lidia,

del derecho de libre creación artística hablan, igualmente de manera indebida, del carácter limitado de todos los derechos y, concretamente, de la posibilidad constitucional de restringir dicho derecho.

${ }^{6} \mathrm{La}$ ausencia de este aspecto lúdico en los toros es lo que parece llevar a GoYTisolo (1969: 106) a concluir que los toros no son arte. Ya que tanto los toreros como los empresarios taurinos llegan a este mundo interesados sobre todo en progresar económicamente, no se puede decir que la distracción o el juego predomine en sus acciones. Pero esto es discutible porque, por un lado, cabe responder que los que llegan movidos por el dinero pueden acabar distrayéndose y, por tanto, creando arte; y por otro lado, podría argüirse que la distracción que supuestamente caracteriza al arte puede ser la que disfruta el espectador, no la del creador.

7 PÉREZ de Ayala, 1943: 800-802 (citado en CAMBRIA, 1974: 111-112). 
y convierte a ésta en arte, es la propia personalidad creativa del torero. Tras sentenciar que sólo hay arte donde hay expresividad, define ésta, de una manera también algo confusa, como «originalidad, modo de poner una nueva criatura en el mundo, con sólo virtualidades espirituales en acción misteriosa de ímpetu creador» ${ }^{8}$.

No obstante, e independientemente de cómo se defina esa gran expresividad de las corridas, para algunos autores, como E. NOEL, el problema reside precisamente en lo fuerte de esa expresividad. Ésta transmite un sentimiento tan bárbaro que por ello, sostiene NoEL, la lidia queda invalidada como manifestación artística. Dice textualmente: «He aquí por qué las corridas no tienen descripción posible; porque son unas emociones fuera de todo arte..., que saltan desde el ruedo al corazón sin transición, ni preparación alguna... Las corridas de toros no son del dominio del arte; son una pesadilla convertida en realidad por una serie de sorpresas violentas e increíbles que pasman mientras se observan, que después de vistas parecen mentira» ${ }^{9}$. Para él, sencillamente no hay arte en la barbarie.

Pero la forma más común de defender el carácter artístico de las corridas, quizá huyendo del peligroso relativismo al que nos puede llevar una estética basada en la subjetiva expresividad, ha consistido en mostrar a éstas como una clara y crucial fuente de verdad. Son manifestaciones artísticas porque en ellas se representa una realidad de gran transcendencia. Para P. HETTER, por ejemplo, se trata de una tragedia al estilo griego, que muestra «la valiente lucha contra la inevitable sentencia del destino», pero que tiene la peculiaridad de glorificar en esa lucha actitudes propias de la cosmovisión hispánica sobre la relación entre el hombre y su sino. Se glorifica, por ejemplo, la creencia de los españoles «en el poder del espíritu humano para transformar los hechos materiales de la existencia, para convertirlos en una obra de arte por pura voluntad, coraje e imaginación» ${ }^{10}$.

Esta consideración de las corridas como espectáculos en los que se representa algo importante es compartida por el filósofo V. GÓmEZ PIN. Para él, la tauromaquia es arte, incluso en un sentido superior al convencional, porque reivindica los orígenes de éste, y es que en ese juego simbólico con el toro, dice, «se está recreando un acto fundamental para la condición humana. Tal acto, se halle o no dado empíricamente en los orígenes, es simplemente aquel por el cual un infante... pasa a ser cabalmente un ser humano». Se trata de un rito sacrificial en el que se representa un acontecimiento determinante que se hallaría en el origen mismo de la civilización y que consiste en negar la pura animalidad ingresando en el reino de la racionalidad. Un ingreso que se recrea perfectamente en la tauromaquia por ser ésta, dice GÓMEZ PIN, «tan rigurosa, elemental, tremenda y gratuita» como dicho ingreso ${ }^{11}$.

Todas estas afirmaciones sobre lo supuestamente recreado en las corridas son obviamente muy controvertidas. No obstante, creo que su discusión resultaría estéril mientras los defensores del valor estético de los toros no rebatan una muy convincente negación de la premisa mayor, la de que los toros son arte porque representan algo.

8 CABA, 1969: 25 (citado en CAMBriA, 1974: 318-319).

9 Noel, 1924: 42 (citado en CAMBria, 1974: 192).

10 HetTER, 1954: 476, 478.

11 GÓmez Pin, 2002: 116 y 222-223. Sobre el simbolismo o significado profundo y trágico de la corrida, vid. también PÉREZ de Ayala, 1943: 1273, 1277; ORTEGA y Gasset, 1960: 74-75, 181, y MadARIAGA, 1954: 122. 
La crítica no sería nueva. Ya la apuntaba A. MACHADO cuando, poniendo sus opiniones en las enseñanzas de su personaje Juan de Mairena a sus alumnos, éste decía: «Vosotros sabéis mi poca afición a las corridas de toros. $\mathrm{Y}$ os confieso que nunca me han divertido. En realidad, no pueden divertirme, y yo sospecho que no divierten a nadie, porque constituyen un espectáculo demasiado serio para la diversión. No son un juego, un simulacro...; tampoco un ejercicio utilitario...; menos un arte, puesto que nada hay en ellas de ficticio o de imaginado» ${ }^{12}$. Una idea en la que insistió J. MOsTERíN, quien criticando al Tribunal que promulgó la sentencia que ha dado pie a este trabajo, le acusó, entre otras cosas, de no comprender lo que es el arte cuando mantuvo que con la prohibición de la Generalitat se había atentado contra la libertad artística. Dijo MosteRín: «Al final de la ópera Carmen, Escamillo torea y don José apuñala a Carmen. Naturalmente la muerte del toro y de Carmen son dos ficciones. El arte es ficción y la ópera es arte. Matar al toro en un escenario no es arte, como tampoco lo sería matar a la actriz que interpreta el papel de Carmen. Sólo un artista mediocre y sin imaginación puede confundir la representación ficticia o artística del dolor y la muerte con la cosa misma» ${ }^{13}$.

En definitiva, ninguno de los argumentos anteriores constituye por sí solo, o en conjunción con los otros, una prueba convincente de que las corridas sean manifestaciones artísticas. Es más, se les podría criticar también en el sentido de que, en el caso de que superasen las objeciones presentadas, la dificultad residiría entonces en que si esos criterios (carácter lúdico, expresivo y representativo) fueran los decisivos para catalogar algo como obra de arte, serían muchas las actividades que cabrían en dicha categoría. ¿No podrían encontrarse razones para mantener que en un partido de fútbol o en un combate de gladiadores, por ejemplo, se lleva a cabo una actividad de distracción en la que se expresan complejos sentimientos que sólo los entendidos apreciarían y en la que se recrean simbólicamente ciertas características esenciales a la naturaleza humana? Quizá, en el fondo, la dificultad de defender que las corridas son arte provenga de la dificultad de los estéticos para definir de manera unívoca este concepto. Una dificultad teórica que ha hecho extenderse entre ellos una teoría institucional del arte que gira en torno a la idea de que la única característica común a todas las obras de arte es justamente el hecho de que han sido reconocidas como tales por ciertas instituciones. Si eso es así, ciertamente todo puede ser arte, incluido los toros, pero sin olvidar que esto sólo se conseguiría a costa de vaciar de todo contenido el término «arte».

\section{LA CRUELDAD CON LOS ANIMALES Y LOS LÍMITES DE LA CREACIÓN ARTÍSTICA}

No hay por tanto argumentos contundentes para apoyar (ni para negar) que el toreo sea un arte. Pero supongamos, por conveniencia discursiva, que las corridas son exhibiciones artísticas. Esto me permitiría retomar la cuestión que dejaba pendiente más arriba de si el maltrato a los animales puede constituir una válida restricción a la libertad creativa.

12 Machado, 1962: 1126 (citado en CAmbria, 1974: 85).

13 En el Prólogo a De LoRA, 2003: 13. 
El derecho a la producción y creación artística, que en el caso de las obras teatrales y operísticas presupone también la libertad de exhibirlas públicamente, es una concreción del derecho a expresar y difundir libremente los pensamientos ${ }^{14}$. Ambos derechos, tanto el particular de la libertad artística como el más genérico de la libre expresión, están reconocidos por el art. 20 de nuestra Constitución. Pero eso no quiere decir que dichos derechos sean ilimitados. El mismo art. 20 de la Constitución afirma, en su apartado cuarto, que estos derechos, en los que se integra la libertad de representar obras teatrales y operísticas, tiene su límite en el respeto a los derechos fundamentales reconocidos en el título I de la Constitución, en los preceptos de las leyes que lo desarrollan y, especialmente, en el derecho al honor, a la intimidad, a la propia imagen y a la protección de la juventud y la infancia ${ }^{15}$. Eso significa que, en el caso más claro, la prohibición de un espectáculo artístico que conllevara la tortura o la muerte de sus protagonistas o de algunos de los integrantes del público no constituiría obviamente un ejemplo de censura, aun cuando tal tortura o muerte fueran un elemento esencial para la comprensión y disfrute de la obra. La prohibición de representación sería legítima en virtud de que los derechos fundamentales a vivir y a no ser torturado, recogidos en el art. 15 de la Constitución, restringen de manera rotunda la libertad creativa. Debemos ahora preguntarnos si esa misma limitación se aplicaría también cuando los torturados o matados en público fueran animales en vez de humanos. O dicho de otra forma, ¿se ajustaría a la Norma Fundamental la ley catalana que prohíbe el maltrato animal en espectáculos?

Evidentemente, eso es algo que no podemos determinar desde una lectura literal de la Constitución. En ella no hallaremos una inmediata restricción de los espectáculos con maltrato animal porque los derechos fundamentales que, como hemos visto, limitan la libertad creativa no admiten actualmente una titularidad no humana. Pero existen otras formas indirectas de determinar la constitucionalidad de la ley catalana. Por ejemplo, encontrando su encaje con otras partes importantes del ordenamiento jurídico que, en cuanto tales, deben ser conformes a la Constitución. En ese sentido puede defenderse la legitimidad de la ley catalana aduciendo que el maltrato que se prohíbe en ella está tipificado como falta en el art. 632.2 del Código Penal vigente ${ }^{16}$. Éste dice textualmente: «los que maltrataren cruelmente a los animales domésticos o a cualesquiera otros en espectáculos no autorizados legalmente sin incurrir en los supuestos previstos en el art. $337{ }^{17}$ serán castigados con la pena de multa de 20 a 60 días o trabajos en beneficio de la comunidad de 20 a 30 días».

14 Tal y como lo ha dejado claro el Tribunal Constitucional en la Sentencia 153/1985, de 7 de noviembre (RTC 1985: 153).

15 De modo similar, el art. 10 del Convenio Europeo para la Protección de los Derechos Humanos y las Libertades Fundamentales (RCL 1979, 2421) consagra el derecho de toda persona a la libertad de expresión cuyo ejercicio, se dice, entraña deberes y responsabilidades, y puede ser sometido a ciertas formalidades, condiciones, restricciones o sanciones previstas por la Ley que constituyan medidas necesarias en una sociedad democrática para, entre otros intereses, preservar la defensa del orden y la persecución del delito, la protección de la salud o de la moral.

${ }_{16}$ Esta falta estaba ya recogida en el Código Penal de 1995, pero no en los anteriores, con la excepción del de 1928, que incluía en su art. 810.3 una falta por la que se castigaba a «... los que públicamente maltrataren a los animales domésticos o los obliguen a una fatiga excesiva» con una pena de multa de 50 a 500 pesetas (citado en SALÀs DARROCHA, 2004).

${ }_{17} \mathrm{El}$ art. 337 dice literalmente: «Los que maltrataren con ensañamiento e injustificadamente a animales domésticos causándoles la muerte o provocándoles lesiones que produzcan un grave menoscabo físico serán 
Es cierto que los detalles de la acción tipificada por dicho artículo no están claros y que la ambigua redacción de éste permite al respecto dos interpretaciones distintas:

1. Que se penaliza el maltrato cruel a los animales domésticos en todo caso y el maltrato cruel a cualesquiera otros animales en espectáculos no autorizados legalmente.

2. Que se penaliza el maltrato cruel a los animales domésticos y a cualesquiera otros en espectáculos no autorizados legalmente.

No obstante, parece actualmente generalizado el acuerdo entre los penalistas de adoptar la primera interpretación. Aducen para ello que el mencionado artículo sólo adquiere sentido si se acepta que la conjunción disyuntiva fue introducida para denotar diferencia, separación o alternativa entre dos supuestos; que si el legislador no hubiera querido tipificar los malos tratos a los animales domésticos fuera de los espectáculos no autorizados, le habría bastado con no distinguir entre animales domésticos y los que no lo son, de modo que así en la ley se condenara el maltrato cruel en dichos espectáculos de todo tipo de animal ${ }^{18}$.

De todas formas, sea cual sea la interpretación válida de este art. 632.2, es innegable que según nuestro ordenamiento jurídico la libertad para la creación artística no es ilimitada y que es legítimo prohibir las manifestaciones de dicha libertad que, no habiendo sido autorizadas por la Administración competente —en este caso, las Comunidades Autónomas - conlleven crueldad con los animales, sean domésticos o no. Es por ello que casi todas las leyes autonómicas sobre protección de animales incluyen la prohibición de tales manifestaciones. Una prohibición que, como hemos visto, recibe su justificación última no en virtud del hecho de que en estas manifestaciones artísticas se vulnere aquellos derechos bumanos fundamentales que según la Constitución podían legítimamente limitar la creación y producción artística, sino más bien

castigados con la pena de prisión de tres meses a un año e inhabilitación especial de uno a tres años para el ejercicio de profesión, oficio o comercio que tenga relación con los animales». La introducción de este artículo (en el capítulo IV del título XVI del Libro II, llamado De los delitos relativos a la flora, fauna y animales domésticos) y la modificación del 632 son resultado de la LO 15/2003, de 25 de noviembre, que modifica la LO 10/1995, de 23 de noviembre, del Código Penal (entrando en vigor el texto reformado el 1 de octubre de 2004). Con ello se refuerza la protección de los animales frente al maltrato, convirtiendo a éste, cuando se lleve a cabo con animales domésticos, en un delito si la conducta es grave, y manteniéndose la falta únicamente para los supuestos leves que no tuviesen las consecuencias previstas para el delito. Asimismo, se introduce como falta el abandono de animales.

18 Esta interpretación no ha sido siempre la dominante. Antes de la reforma del Código Penal, en 2003, los tribunales se inclinaban por la segunda interpretación. Claros ejemplos de ello son las Sentencias ARP 1998/5198 y ARP 2000/615, de las audiencias provinciales de Cantabria y Tenerife, respectivamente. En el ámbito de los penalistas, el mejor representante de la adopción de esta segunda interpretación es VALLDECABRES OrTiZ (en Vives ANTÓn, 1996: 2182). Sin embargo, tal y como apunta SALÀs DARROCHA, 2004, la primera interpretación cobra más fuerza que la segunda después de la citada reforma, pues a partir de entonces si siguiéramos la segunda nos encontraríamos con la contradicción de tipificar al mismo tiempo como delito y como acto no punible el maltrato de animales domésticos. Ya que adoptando esa segunda interpretación del art. 632.2, el maltrato de animales domésticos, por un lado, no sería punible al realizarlo en espectáculos autorizados, y por otro, llegaría incluso a ser delito, en virtud de la tipificación que como tal se establece en el art. 337, introducido en la reforma, del maltrato (con ensañamiento y resultado lesivo) de cualquier animal doméstico. Por la primera interpretación también optan, antes de la introducción del art. 337, y sólo por las razones gramaticales señaladas, Robles PlanAs, 1996: 705, e Higuera GuImERÁ, 1994: 64. En la jurisprudencia, tal forma de entender el art. 632 aparece, por ejemplo, en las sentencias de la Audiencia Provincial de Valencia de 9 de diciembre de 2000 (ARP 656/2000) y de la Audiencia Provincial de Segovia de 15 de septiembre de 1998 (ARP 1998/3755). 
porque dichos espectáculos aparecen tipificados como falta en un Código Penal que es conforme a la Constitución.

Ahora bien, ¿cómo se puede asegurar que tal tipificación es constitucional? ¿Cómo puede justificar el legislador dentro del marco constitucional que el espectáculo cruel con animales es una falta punible? Lamentablemente, en este caso, como en muchos otros, el legislador no ha sido explícito, y han sido los penalistas quienes, por medio de técnicas hermenéuticas, se han dedicado a buscar la posibles razones últimas de la tipificación.

Y en esa búsqueda lo primero que han dejado claro es que si se protege a los animales no se hace porque se considere que éstos tienen derecho a no sufrir, pues éste es un derecho que, según la Constitución, gozan exclusivamente los humanos. Por tanto, si el legislador penaliza el maltrato de los animales, sólo puede hacerlo porque tal conducta perjudique de cierta forma a los seres humanos. Y resulta que esta consideración antropocéntrica de nuestra relación con los animales se hace especialmente evidente en el caso que nos ocupa, el de la tipificación como falta del maltrato de animales en espectáculos no autorizados. Pues esta falta, junto con otras tan dispares como la suelta de animales feroces o dañinos, la expedición de moneda falsa o el abandono de jeringuillas, adquieren su sentido en el título III del Libro III del Código Penal como diferentes instrumentos al servicio de la protección del bien jurídico de los intereses generales (de los seres humanos).

Hay que preguntarse ahora en qué consiste realmente este bien jurídico para cuya protección se requiere tal cajón de sastre de conductas punibles. ROBLES PlANAS llega a la conclusión de que «habida cuenta de la evolución que ha sufrido el Título en cuestión y de la ubicación sistemática de las faltas que a él se refieren, cabe entender por intereses generales solamente aquellos valores latentes en la sociedad, no individualizables in se pero con repercusiones indirectas sobre los individuos, y que requieren protección porque sus ataques suponen un desequilibrio en el proceso de comunicación e interacción del sistema social» ${ }^{19}$.

¿Y cuál es ese valor socialmente tan importante que se pondría en peligro en el caso concreto de no penalizar la exhibición pública de la crueldad con los animales? Para Robles Planas, se trataría del «sentimiento de compasión que tiene la sociedad respecto de los animales». Y añade que con la falta que nos ocupa se estaría tutelando «la benevolencia del trato, en aras de la evitación del sufrimiento y de la crueldad, los cuales generan en la sociedad un sentimiento de reproche cuando son innecesarios. Sólo así se puede entender que no se hayan tipificado especialmente las conductas en las que, no existiendo malos tratos, se produzca un resultado de lesiones o muerte en los animales. Y ello porque, en realidad, lo que se quiere proteger no es el animal sino a la sociedad, en tanto que ésta rechaza la crueldad y la violencia innecesarias para con los animales y tiene un interés general en evitarla en la medida en que genera un sentimiento de compasión» ${ }^{20}$.

19 Robles Planas, 1996: 687.

20 Robles Planas, 1996: 703-704. En la misma dirección apuntan RodRíGUEZ Devesa (1995: 398) y Roca Agapito (2000). Para este último, cuando se dice que los animales nunca pueden ser sujetos pasivos del delito, la razón de tipificar el maltrato cruel de los animales tiene que ser necesariamente la «lesión de los sentimientos de quienes presencian tales hechos o tienen noticias de ellos» (401). Discrepante es la postura, 
Debe indicarse también que, aunque la introducción del art. 337 en la reforma del Código Penal de 2003, en el que se tipifica como delito el maltrato cruel de animales domésticos en cualquier circunstancia, podría verse como un cierto alejamiento del señalado antropocentrismo, en realidad no es así. Su ubicación en la sección de los delitos contra el medio ambiente ha hecho creer a algunos que comienza a haber un interés en el legislador por proteger, por sí mismos, el bienestar y la integridad de los animales, por entrever ciertos derechos propios de los animales. Pero la creencia resulta infundada si nos percatamos de que en la reforma el mencionado delito se incluyó en un capítulo, el IV, que engloba penas pensadas para proteger la biodiversidad o la pluralidad de especies, bienes que no dejan en ningún momento de ser concebidos como valiosos patrimonios de los seres bumanos.

De todas formas, entiendo que, a pesar de la señalada ubicación, tras la reforma, del delito de maltrato de animales domésticos, su justificación antropocéntrica se basa más en el sentimiento de compasión que en la protección de los bienes patrimoniales. Ya que si la intención del legislador hubiera sido meramente la conservación de especies (de animales domésticos) no hubiera tenido ninguna necesidad de reservar el castigo para las acciones que consistan en maltrato «con ensañamiento e injustificadamente». El legislador hubiera conseguido mejor su objetivo penalizando exclusivamente aquello que conlleva a la desaparición de las especies, no el sufrimiento de sus miembros. En ese sentido, me inclino más a compartir la opinión expuesta por QUINTERO OLIVARES y otros (2005) según la cual, partiendo de la base de que los animales no tienen derechos, se puede afirmar que lo que se tutela en el art. 337 es una relación con las especies animales domésticas que no resulte ofensiva para los sentimientos de respeto y protección que la comunidad entiende que deben presidir nuestros vínculos con el mundo animal.

\section{LA EXCEPCIÓN TAURINA}

De lo anterior se deduce que las leyes actuales sobre protección animal siguen basándose en una antigua creencia: la de que no debemos ser crueles con los animales porque, sencillamente, con ello nos hacemos daño a nosotros, los seres humanos. Ha habido, eso sí, cierta evolución en la determinación de cuál puede ser el tipo de perjuicio que nos provoquemos al maltratar a los animales. Así, ya no se piensa, como mantuvieron AQUINO o KANT ${ }^{21}$, que lo grave de ese maltrato provenga de que con él los humanos acaban siendo más crueles con sus congéneres. Más bien se cree que el problema está en que con tal conducta ofendemos la sensibilidad de muchos humanos que se identifican con el sufrimiento animal o que simplemente lo proyectan en otros humanos. Y es esta sensibilidad contra la crueldad la que se considera en nuestras leyes un bien jurídico esencial para la paz social, que, como tal, debe ser protegido. Esto permite mantener que por la salvaguarda de ese bien tan decisivo, resulta legítimo limitar la creación artística impidiendo su plasmación en crueles espectáculos.

defendida con argumentos insuficientes e incomprensibles, de HigUERA GUIMERÁ (1998), según la cual el bien que se pretende proteger con esta normativa es aquel conjunto de obligaciones de carácter bioético que sostiene el hombre para con los animales, conjunto de obligaciones o deberes en el sentido de tratar a los mismos con benevolencia y no maltratarlos ni física ni psíquicamente, y menos aún matarlos o exterminarlos con crueldad e injustificadamente.

${ }_{21}$ T. DE AquinO, 1570: 463; y KANT, 1775-1781: 287. 
Pero aquí es necesario introducir una matización que confiere cierta incongruencia a la argumentación del legislador. Me refiero a la diferenciación jurídica que nuestro Código Penal, y más concretamente el art. 362, hace entre animales domésticos y los que no lo son ${ }^{22}$. Como vimos antes, y según la interpretación más extendida, en dicho artículo se tipifica como falta todo espectáculo de crueldad con animales domésticos (siempre que no conlleve maltrato con ensañamiento e injustificadamente causándole la muerte o provocándole lesiones que produzcan un grave menoscabo físico, lo que ya sería considerado delito y estaría penado, por el art. 337, incluso con la cárcel), pero si los animales maltratados no son domésticos entonces el espectáculo sólo estaría prohibido si carece de autorización administrativa. Cabría preguntarse hasta qué punto que el animal sea o no doméstico es algo tan importante como para atenuar esa regla general de que por el interés general de la paz social no se debe exhibir públicamente el maltrato cruel ${ }^{23}$. La ausencia de una justificación por parte del legislador para realizar esta diferenciación y el hecho de que los espectáculos con animales salvajes que suele autorizarse por la Administración suelen ser, como veremos más adelante, los taurinos hace pensar que lo que se pretendía desde un principio era garantizar especialmente la permisividad de este tipo de espectáculos. Y una permisividad que parece pretenderse además de una forma encubierta, disfrazando el propósito fundamental de proteger la lidia con el recurso a una complicada e inexplicable diferenciación de animales en categorías tan amplias y vagas como la de domésticos y no domésticos ${ }^{24}$.

Pasemos por alto, sin embargo, este extraño encubrimiento de la pretensión del legislador de excluir las corridas de la prohibición general de espectáculos crueles y preguntémonos por las posibles razones que el legislador podría aducir, pues nunca las hace explícitas, a favor de esa pretendida exclusión. Es decir, ¿cómo podríamos defender de forma admisible que aun cuando la producción de un espectáculo que conlleva sufrimiento animal deba prohibirse por razones de interés general, sin embargo, cuando el animal que sufra sea el toro de lidia, entonces debemos permitirlo?

F. SAVATER ha intentado justificar esta excepcionalidad de las corridas relativizando la gravedad del sufrimiento. Para él, «se puede criticar la crueldad de los toros, que es evidente, pero no tenemos que olvidar que todo es cruel. En cualquier aspecto de nuestra vida aparece el sufrimiento. Si no, que se lo pregunten a los atletas que se pri-

22 Sobre la injustificable diferencia en el grado de protección de los animales domésticos y de los que no lo son, partiendo como se hace del bien jurídico de la compasión, vid. RoBLes Planas, 1996: 706.

23 Segrelles de AREnAZA (2000: 1163) ha criticado de esta forma la arbitrariedad de condenar el maltrato cruel sólo en los espectáculos autorizados: «Tampoco me parece correcto (además de que el único maltrato que se castigue sea el cruel) castigar el maltrato sólo en espectáculos no autorizados porque, a contrario, significa que en los autorizados está permitido el maltrato cruel. Las consecuencias de esta regulación ya se ha plasmado en la jurisprudencia menor. Así, la SAP de Segovia de 15 de septiembre de 1998 (ar. 3755) absuelve a una persona que maltrató a un caballo hasta la muerte, puesto que éste no se puede considerar animal doméstico, ni el maltrato se realizó en un espectáculo público. Es lamentable, por decirlo con un término suave, que se pueda maltratar a un caballo, sin respuesta penal alguna. Si lo que se desea es evitar que la "fiesta nacional" pueda subsumirse en el tipo penal se ha de buscar otra forma de tipificar el maltrato de los animales».

24 Robles Planas $(1996,705-706)$ ha insistido en la ambigüedad del término «animales domésticos», que, aunque abarque claramente a los animales de compañía y excluya a los fieros y salvajes, resulta indefinido respecto a los amansados o domesticados. Debido a esta falta de claridad conceptual, el Derecho administrativo, sobre todo el autonómico, ha producido en su legislación sobre protección de animales una gran diversidad de concepciones extrapenales del término. Como resumen de estas diversas concepciones, vid. la aportación de M. a Marqués i Banqué, en SuÁrez-Mira Rodríguez, 2004: 1267-1269, y Requejo Conde, 2007: 3-4. 
van de muchas cosas para poder batir récords o mejorar sus marcas. Incluso el amor es cruel y la enseñanza, porque a qué niño le gusta aprender a leer o a escribir si no es por obligación de sus padres» ${ }^{25}$. El argumento, que desentona con la fineza argumentativa a que SAVATER nos tiene acostumbrados, resulta sin embargo claramente inadmisible. Pues si lo que quiere defender es que todos los sufrimientos son idénticos en el sentido de que poseen la misma relevancia moral, es innegable que, en tal caso, al igual que no censuramos el sufrimiento de atletas o escolares, tampoco deberíamos reprobar el infligido al toro en la plaza; pero entonces cabría añadir que en igual medida careceríamos de legitimidad para criticar el provocado a los inocentes por despiadados torturadores o por injustas guerras. Una consecuencia ésta verdaderamente indeseable con la que SAVATER parece no haber contado a pesar de su obviedad.

Lo que necesitamos por tanto en este tema no es tanto una relativización del sufrimiento como una explicación de por qué a veces hemos de poner en suspenso ese criterio moral, universal, de procurar evitar el sufrimiento innecesario. Es decir, ¿qué otro principio estaría en juego en la defensa de los toros que fuera de tanta relevancia como para anteponerse a dicho criterio? Para ORTEGA Y GASSET se trataría de un principio derivado del reconocimiento de una especie de estética deslumbrante que nos acercaría a lo trascendental. Dice que aunque el derramamiento de sangre suele producirnos terror y asco porque supone sacar de su intimidad esa sangre que simboliza el verdadero «dentro» o intimidad de la vida, ese terror y asco no se da cuando se produce con gran efecto estético, «cuando brota en el morrillo de toro bien picado y se derrama a ambos lados. Bajo el sol, el carmesí del líquido brillante cobra una refulgencia que no lo transustancia en joyel» ${ }^{26}$. Y por ello, sacrificar con esa estética al toro es, añade ORTEGA, algo así como un honor para éste ${ }^{27}$.

Pero el camino que ORTEGA abre con este intento de limitar la ética desde la estética resulta, cuanto menos, peligroso. Quizá sin advertirlo, el propio ORTEGA da las claves para percatarnos de adónde puede llevarnos su razonamiento. Así, queriendo resaltar el efecto embriagador que la sangre produce en el público y que es parte de esa sublime experiencia estética que se da en la lidia, dice textualmente: «los romanos iban al circo como a la taberna, y lo mismo hace el público de las corridas de toros: la sangre de los gladiadores, de las fieras, del toro, opera como droga estupefaciente... La sangre tiene un poder orgiástico sin par» ${ }^{28}$. Por tanto, si el efecto impactante del derramamiento de la sangre que ponía en suspenso la condena ética del sufrimiento del toro, que nos permitía, en palabras de ORTEGA, tomarnos unas «vacaciones de

25 Entrevista a F. SAVATER en El Mundo, de Euskadi, 2 de agosto de 1991. El mismo argumento se repite en su artículo «Las cornadas de Europa», aparecido en el diario El País con fecha de 22 de diciembre de 1991: 13.

26 ORTEGA Y GASSET, 1943: 465n.

27 Así dice en Ortega y GASSET, 1960: 74-75 (cit. en CAMBRIA, 1974: 136), hablando de la caza pero con clara referencia a los toros: «No está dicho siquiera que el mayor y más moral homenaje que podemos tributar en ciertas ocasiones a ciertos animales no sea matarlos con ciertas mesuras y ritos». V. GómEZ PIN, sin embargo, no se contenta con justificar el sufrimiento del toro como una especie de excepción ética, sino que defiende que se trata de una exigencia moral ineludible. Las corridas son como un rito en el que con el sacrificio del animal el ser humano reconoce en principio su animalidad para inmediatamente admitir también nuestra peculiaridad racional. Parece que viene a mantener que no hay otra forma de conseguir esa concienciación; que hemos de provocar todo ese sufrimiento al toro para que así nos demos cuenta de que somos animales racionales. Vid. GÓMEZ PIN, 2002: 42-43, 58-59, 97, 149, 166, 218, 219-221 y 223.

28 ORTEGa y GaSSET, 1943: 465. 
humanidad», resulta ahora que no lo produce exclusivamente la sangre animal, ¿por qué no tomarnos también dichas vacaciones ante la lucha de gladiadores o algún otro espectáculo que conllevase la tortura de seres humanos?

De todas formas, parece que este argumento orteguiano tampoco es el que ofrecería la mayoría de los españoles, incluidos los legisladores, si tuvieran que defender las corridas. El argumento más común al respecto es el que podemos encontrar, no sin cierta dificultad, en las leyes autonómicas que autorizan dichos espectáculos al amparo de lo estipulado en los mencionados artículos del Código Penal. Según estas leyes, se permiten los espectáculos taurinos sólo por su carácter tradicional. Se les concede valor por el hecho de formar parte del patrimonio cultural español; porque constituyen un rasgo constitutivo de la historia y de la identidad de nuestro país.

Esta general disposición a autorizar los festejos taurinos en virtud de su raigambre se da tanto en las legislaciones más protectoras como en aquellas otras que los permiten sin favorecerlos. Como ejemplo de las primeras destaca la Ley 3/1992, de 18 de marzo, de protección de animales y plantas de la Comunidad Autónoma de Cantabria, que justifica, en su art. 6, la excepcionalidad de los espectáculos taurinos porque éstos, «como conjunto de actividades artísticas y culturales, son exponentes de nuestro acervo histórico», y exige de la Diputación Regional de Cantabria que vele «por su pureza, realizando las oportunas inspecciones anteriores y posteriores al espectáculo, en garantía de que el animal no se encuentre limitado en su poder y defensas, como principio valedor de la equidad en la lucha que la fiesta requiere». Con una pretensión similar, la Ley 1/1993, de 13 de abril, de la Comunidad Autónoma de Galicia, de protección de animales domésticos y salvajes en cautividad, establece en su preámbulo que «excepcionalmente, permite esta ley la celebración de los espectáculos tradicionales en los que intervengan animales siempre que se vengan celebrando consuetudinariamente, basándose en la necesidad e interés de pervivencia del patrimonio histórico-cultural de las costumbres de los distintos lugares de Galicia» ${ }^{29}$.

Por otro lado están las leyes que aun reconociendo la conveniencia de evitar la expansión de este tipo de espectáculos, los autorizan. Y lo hacen apelando también al criterio de la tradición. Un ejemplo es la Ley 3/1988, de 4 de marzo, de la Comunidad Autónoma de Cataluña, a la que se refería la sentencia comentada al principio de este trabajo. Dicha ley prohíbe en su art. 4 «el uso de animales en espectáculos, peleas y otras actividades si ello puede ocasionarles sufrimiento o pueden ser objetos de burlas o tratamientos antinaturales, o bien si puede herir la sensibilidad de las personas que los contemplan»; en particular, «la lucha de perros, la lucha de gallos de pelea, el tiro al pichón y demás prácticas asimilables». No obstante, quedan fuera de la prohibición, además de las autorizadas competiciones de tiro al pichón, la fiesta con novillos sin muerte del animal (corre-bous) «en las fechas y localidades en las que tradicionalmente se celebren», y la fiesta de los toros «en aquellas localidades en donde, en el momento de entrar en vigor la presente ley, existan plazas construidas para celebrar dicha fiesta».

${ }^{29}$ Igualmente poco restrictivas en la excepción taurina pero sin apelaciones claras a la justificación tradicionalista son la Ley Foral 7/1994, de 31 de mayo, de la Comunidad Foral de Navarra (art. 4); la Ley 5/1995, de 22 de marzo, de la Comunidad Autónoma de La Rioja (art. 6); la Ley 6/1993, de 29 de octubre, de la Comunidad Autónoma del País Vasco (arts. 3, 4 y 22), y la Ley 11/2003, de 24 de noviembre, de la Comunidad Autónoma de Andalucía (arts. 2 y 4 ). 
En el art. 4 de la Ley 1/1992, de 8 de abril, de la Comunidad Autónoma de las Islas Baleares, se reproduce el mismo esquema de la ley catalana permitiendo las corridas sólo en las plazas fijas existentes al entrar en vigor la ley y exigiendo una cierta antigüedad a los demás espectáculos festivos con uso de animales ${ }^{30}$, incluidos los encierros, que deben haberse «celebrado en forma ininterrumpida durante cien años, y siempre que no supongan tortura, lesiones o muerte del animal». Y añade: «en ningún caso, las fiestas en que los animales puedan ser objeto de malos tratos gozarán de ningún tipo de apoyo o subvención de instituciones públicas de las Baleares» ${ }^{31}$.

Merece la pena añadir, por último, una inesperada consecuencia para el legislador estatal suponiendo que fuera cierta la pretensión que más arriba le atribuíamos de desarrollar leyes con las que disimuladamente garantizaría la permisividad de los toros. Esa forma no manifiesta de hacerlo, recurriendo por un lado a diferenciar espectáculos según se usen o no animales domésticos, y por otro, no especificando el tipo de espectáculos con animales no domésticos que pueden ser autorizados, ha concedido tanta discrecionalidad a las administraciones autonómicas que en una de ellas, la canaria, se permiten las peleas de gallos (prohibidas en el resto de España) y, lo que es más interesante para nosotros, no se autorizan las corridas de toros. Aun así, lo destacable aquí es que el criterio para permitir las primeras y prohibir las segundas sigue siendo el de la tradición, y con él, la diferenciación entre las que son y han sido habituales en Canarias, las peleas de gallos, y las que nunca han despertado gran afición en dicha Comunidad, como es el caso de las corridas de toros.

\section{TRADICIÓN VERSUS RAZÓN}

Si por tanto es el criterio de la tradición o el patrimonio cultural el que suele servir para excluir la lidia (y otros espectáculos) de la prohibición de exhibir públicamente el maltrato de animales ${ }^{32}$, debemos preguntarnos si se trata de un criterio convincente. ¿Es de tanta relevancia ética el criterio de la tradición como para que se anteponga a

30 Con un carácter algo más permisivo, la Ley 1/1990, de 1 de febrero, de la Comunidad de Madrid, en su art. 4, atenúa la exigencia de que los espectáculos taurinos se celebren en los lugares habituales permitiendo al mismo tiempo que se extiendan a otras localidades si reciben la autorización previa de las autoridades competentes.

31 Actitud similar es la que ha adoptado el legislador canario respecto a las peleas de gallos. En el Preámbulo de la Ley 38/1991, de 30 de abril, de la Comunidad Autónoma de Canarias, se reconoce lo especialmente indeseable de que se haga negocio lucrativo con espectáculos que, como las peleas de gallos, se basan fundamentalmente en el maltrato de animales, y que el hecho de que sean actividades tradicionales no atenúa lo impropio de estas actividades en una sociedad moderna y evolucionada. Por ello, se dice, esta Ley propicia su desaparición no autorizando nuevas instalaciones ni permitiendo ayudas desde la Administración (art. 5).

32 Éste es también el criterio con el que algunos eurodiputados españoles han conseguido introducir en la legislación comunitaria sobre protección de animales una cláusula de excepción para salvaguardar las costumbres tradicionales y más concretamente, las corridas de toros. Es lo que pasó, por ejemplo, cuando con la negociación del Tratado de Amsterdam, firmado en 1997, se conseguía sustituir la declaración núm. 24 del Tratado de la Unión Europea con la intención de «garantizar una mayor protección y un mayor respeto del bienestar de los animales como seres sensibles». A tal fin se acaba pidiendo a los Estados miembros que, a la hora de aplicar las políticas comunitarias, tengan plenamente en cuenta las exigencias en el bienestar de los animales, pero «respetando al mismo tiempo las disposiciones legales o administrativas y las costumbres de los Estados miembros relativas, en particular, a ritos religiosos, tradiciones culturales y patrimonio regional». En similares términos quedaba redactado el art. III-121 de la Constitución europea, finalmente no refrendada en todos los países: «La Unión y los Estados miembros tendrán plenamente en cuenta las exigencias del bienestar de los animales como seres sensibles, al tiempo que respetarán las disposiciones legales o administrativas y los usos 
esos bienes jurídicos, los intereses generales, que se pretenden defender al limitar la libertad artística con la mencionada prohibición?

Es cierto que al igual que los legisladores, algunos ensayistas han defendido las corridas apelando a su antiguo origen y a su constante presencia en las costumbres españolas, de modo que constituyen un valioso patrimonio y seña de identidad para los españoles. Para ORTEGA Y GASSET, por ejemplo, no puede escribirse la historia de España sin entender la realidad taurina ${ }^{33}$. Y TIERNO GALVÁN lo explicaba aduciendo que los toros testimonian y expresan la unidad de los distintos pueblos de España de la misma manera que la ópera exhibe la psicología profunda de la nación italiana ${ }^{34}$. Para F. VILLALÓN, «puede decirse, sin temor a caer en la hipérbole, que el taurinismo llega a constituir una característica fuertemente burilada en el temperamento español» ${ }^{35}$. Incluso PÉREZ DE AYALA, partidario de prohibir las corridas por su nocividad social, llega a reconocer su tremenda utilidad para conocer la auténtica forma de ser de los españoles. Mantiene que «son una cosa tan nuestra, tan obligada por la naturaleza y la historia como el habla que hablamos. Nacieron con España y es de barruntar que no concluyan sino cuando ella concluya» ${ }^{36}$.

Lo primero que puede destacarse de este tipo de afirmaciones es su carácter obviamente exagerado. Las corridas no pueden ser tan definitorias de la idiosincrasia española porque, contrariamente a lo que mantienen esos ensayistas, aparecen en la historia de España muy recientemente. Aunque no falta quien sitúa su origen en los tiempos míticos ${ }^{37}$, las corridas, tal y como las conocemos actualmente, no aparecen hasta el siglo XVIII ${ }^{38}$.

De todas formas, creo que el principal error en aquellos que pretenden justificar la excepción legal de las corridas en virtud de su carácter tradicional no está en que sobreestimen el valor patrimonial o idiosincrásico de éstas; está en el propio hecho de utilizar el criterio de la tradición para justificar la excepción. Pues se trata de un criterio que por sí solo no puede fundar un juicio moral. No es una razón válida para prescribir cierto comportamiento el mero hecho de que éste responda a una costumbre. Si conservamos las tradiciones es porque entendemos que transmiten valores positivos o, al menos, no transmiten ninguno negativo. Sería irracional que en el momento del declive de la Santa Inquisición, o incluso actualmente, una vez conocidos sobradamente sus inutilidades y excesos, alguien defendiese la persistencia, o el reestablecimiento, de dicha institución simplemente porque constituye algo propio de la historia de nuestro país.

En definitiva, desde la más simple lógica de la argumentación ética, uno puede, para mantener cierta práctica, aducir razones que nos convenzan de su conveniencia, y se puede discutir si dichas razones son correctas; pero lo que no es aceptable, porque

de los Estados miembros, en particular por lo que respecta a los ritos religiosos, las tradiciones culturales y los patrimonios regionales».

33 Ortega y Gasset, 1958: 155 (citado en De Lora, 2003: 291).

34 Tierno Galván, 1987: 48-49 (citado en De Lora, 2003: 291).

35 Villalón, 1986: 16 (citado en De LORA, 2003: 291).

36 Pérez De Ayala, 1925: 180 y 186 (citado en De Lora, 2003: 291).

37 En Villalón, 1986: 22, y Fernández Rodríguez, 1999, 122 (citados en De Lora, 2003: 286), se sostiene que Hércules ya había toreado en su décima tarea, al arrebatarle a Gerión, el monstruo que reinaba en España, sus bueyes rojos y dárselos a Euristeo.

38 Según Ortega y Gasset (1958: 153-155, citado en De LoRA, 2003: 289) aparecen exactamente en 1728. Antes de ese año sólo existiría un espectáculo en el que los nobles, a caballo, rejoneaban y mataban al toro. Los que a pie ayudaban a esos rejoneadores serán, con el tiempo, los actuales matadores de toros. 
ni siquiera es una razón moralmente relevante, es afirmar que algo se deba hacer sólo porque siempre, o casi siempre, se haya hecho.

Por tanto, para examinar racionalmente la permisividad de las corridas ha de considerarse básicamente si se trata de una costumbre que merezca ser conservada. Este requisito se hace más inexorable cuando se acepta, como ha quedado reflejado en las leyes de nuestro país, que la exhibición del maltrato animal debe evitarse porque erosiona la convivencia y ofende la sensibilidad de muchos. Resulta entonces que los que quieran defender la lidia desde un punto de vista racional se han de enfrentar, antes que nada, al reto de demostrar que los valores transmitidos por esta práctica son positivos; que en el caso de que en ellas se mostrara la idiosincracia española, ésta fuera tan aceptable, y las corridas tan insustituibles en su promoción, que se hiciera evidente la conveniencia de aceptarlas como una excepción a la regla general de prohibir crueles espectáculos.

Pero los defensores de las corridas no suelen afrontar esta exigencia básica para mantener su posición. Y eso, el mostrar lo valioso de tales espectáculos, constituye una tarea ineludible para ellos, sobre todo cuando sí han aparecido en escena autores empeñados en señalar sus aspectos negativos. Desde la aceptación de que los toros tienen un significado muy hondo, que afecta directamente a la configuración sociológica, psicológica y moral del pueblo español, el ensayista de finales del XIX y principios del XX, E. NoEL, los criticó porque en tal espectáculo se manifiestan, más que las virtudes, todos los vicios de dicho pueblo. En los toros se plasma y promueve una forma de ver la vida que subterráneamente ha conseguido unificar las dispares regiones españolas en unas costumbres que han impedido el progreso de nuestro país y la asimilación por parte de sus ciudadanos de los grandes ideales de la Modernidad. Esa cosmovisión, causa de los males de España, es llamada por NOEL «flamenquismo» y se encarna de manera ejemplar en nuestro símbolo nacional, el torero ${ }^{39}$. Así dice: «de las plazas de toros salen estos rasgos de la estirpe: la mayor parte de los crímenes de la navaja; el chulo; el hombre que pone la prestancia personal sobre toda otra moral; la grosería; la ineducación...; el odio a la ley; el bandolerismo; esa definición extraña del valor que se concreta en la palabra riñones y que ha sido y será el causante de todas nuestras desdichas...; el "apachismo" político; todos, absolutamente todos los aspectos del caciquismo y del compadrazgo» ${ }^{40}$.

Podrían no compartirse las acusaciones de NOEL, pero lo que resulta innegable es que, con ellas, los defensores de las corridas lo tienen aún más difícil. Además de contestarlas, han de aportar razones de la conveniencia de las corridas; razones que, no lo olvidemos, deben ser de tanto peso como para contrarrestar el asumido principio de que la existencia de espectáculos con maltrato animal atenta contra intereses sociales importantes.

Y yo creo que a los defensores de la lidia aún se les puede exigir algo más. Pues incluso suponiendo que se pudiese demostrar, como se le exige, que la sociedad se beneficiaría de alguna manera de las corridas, cabría preguntarse si dicha sociedad, de humanos, es lo único que debe importar en las decisiones morales que implican a seres no humanos. Uno podría plantearse que quizá el problema de la lidia no esté en ver si beneficia o no a los humanos, sino en el hecho de analizarla habitualmente desde una

39 NoEL, 1912: 41-42 (citado en CAmbria, 1974: 187).

40 Noel, 1967: 161-162 (citado en CAmbria, 1974: 194-195). 
moral incongruente que dice preocuparse por el bienestar y el respeto a los animales mientras se olvida de ellos cuando intereses humanos, muchas veces de carácter secundario, lo requieren. Estas incoherencias se hacen evidentes en la legislación que aquí estamos considerando y sólo se superarán, pienso, cuando cojamos por los cuernos al toro de nuestras relaciones con lo animales. Dichas relaciones están basadas en un insostenible especieísmo que diferencia moralmente a los seres vivos en virtud exclusivamente de su pertenencia o no a la especie Homo sapiens. Esto conduce a concebir a muchos animales, sólo por no ser humanos, como meras cosas, que sólo importan si son instrumentalmente valiosos para los humanos. Y todo eso a pesar de que tales seres pueden ser idénticos a los humanos en algo tan significativo como su capacidad de sufrir ${ }^{41}$. Sólo cuando se supere esta irracional discriminación moral de muchos animales se estará en condiciones de legislar adecuadamente en temas relacionados con el maltrato de animales. En España se han dado últimamente algunos pasos legislativos importantes en esta dirección. Por ejemplo, la pretensión del grupo socialista en el Parlamento español, finalmente frustrada, de incluir en la reforma del Código Penal de 2003 un título exclusivo para los derechos de los animales; o la iniciativa de ese mismo grupo, actualmente pendiente de aprobación parlamentaria, de que el Gobierno se adhiera al Proyecto Gran Simio, una organización internacional que lucha por que se les conceda a los grandes simios los derechos básicos a la vida, a la libertad y a no ser torturado. Pasos importantes en el acercamiento a ese objetivo último que debería ser el de legislar desde el reconocimiento constitucional de un derecho básico de todos los seres sintientes a no sufrir innecesariamente; un derecho esencial que, de ser asumido, nos obligaría a no someter el bienestar básico de los toros a intereses humanos como el de de la mera diversión, el disfrute de manifestaciones supuestamente artísticas o la transmisión de cuestionables valores idiosincrásicos ${ }^{42}$.

\section{BIBLIOGRAFÍA}

CABA, P., 1969: Los toros en España, t. III, Madrid, Orel.

CAmbria, R., 1974: Los toros: tema polémico en el ensayo español del siglo XX, Gredos.

De Aquino, T., 1570: Suma contra los gentiles, Porrúa, 1977.

DE LorA, P., 2003: Justicia para los animales, Alianza Editorial.

FERnÁNDEZ Rodríguez, T. R., 1999: «Los toros bravos», en S. MuÑoz Machado (ed.), Madrid, Civitas.

Gómez Pin, V., 2002: La escuela más sobria de vida. Tauromaquia como exigencia ética, EspasaCalpe.

Goytisolo, J., 1969: «Mr. Hemingway va a ver corridas de toros», en J. GoyTisolo, España y los españoles, Lumen, 2002.

Hetter, P., 1954: «The Aesthetics of the Fiesta de los Toros», The Journal of Aesthetics and Art Criticism, núm. 12.

Higuera GuimerÁ, J. F., 1994: «La protección penal de los animales en España», Documentación Jurídica, núm. 79.

${ }^{41}$ Estas críticas a la moral antropocéntrica las he desarrollado en otros trabajos. Vid., por ejemplo, LARA, 2006 y 2007.

${ }_{42}$ Deseo agradecer a O. CAMPOS y a P. DE LORA sus útiles comentarios al borrador de este trabajo. 
- 1998: «Los malos tratos crueles a los animales en el Código Penal de 1995», Actualidad Penal, núm. 17.

KANT, I., 1775-1781: Lecciones de Ética, Crítica, 1988.

LARA, F., 2006: «La entidad moral de los animales y nuestras obligaciones con ellos», Signos Filosóficos, núm. 8.

— 2007: «El valor de los animales y la utilidad de los derechos», en J. M. GARCÍA GÓMEZHeras y C. Velayos (eds.), Responsabilidad política y medio ambiente, Madrid, Biblioteca Nueva.

Machado, A., 1962: «Juan de Mairena», en Obras Completas (4. . ed.), Madrid, Plenitud.

MadariagA, S., 1954: «Spanish tradition», en Essays With a Purpose, London, Hollis \& Carter.

Noel, E., 1912: El flamenquismo y las corridas de toros, Bilbao.

- 1924: Raza y alma, Guatemala.

- 1967: Escritos antitaurinos, Madrid, Taurus.

Ortega y Gasset, J., 1943: «Prólogo a Veinte años de caza mayor, del Conde de Yebes», en J. Ortega y Gasset, Obras Completas, vol. VI, 7. ª ed., Madrid, Revista de Occidente, 1973.

- 1958: Una interpretación de la historia universal, Madrid, Revista de Occidente-Alianza Editorial, 1979.

- 1960: La caza y los toros, Madrid, Revista de Occidente.

Pérez de Ayala, R., 1925: «Política y toros. Ensayos», en Obras Completas de Ramón Pérez de Ayala, t. XII, Madrid, Renacimiento.

- 1943: Política y toros. Obras Completas, t: III, Madrid, Aguilar, 1963.

Quintero Olivares, G., et al., 2005: Comentarios a la Parte Especial del Derecho Penal, 5. a ed. revisada, Thomson-Aranzadi.

Requejo Conde, C., 2007: «El delito de maltrato a los animales», La Ley, núm. 6.690.

Robles Planas, R., 1996: «Las faltas contra los intereses generales en el nuevo Código Penal (a la vez, una contribución al análisis dogmático de las faltas en Derecho penal)», Actualidad Penal, núm. 36.

Roca AgAPito, L., 2000: «Algunas reflexiones sobre los animales y el Derecho penal. En particular el art. 631 del Código Penal», Actualidad Penal, núm. 18.

Rodríguez Devesa, J. M., 1995: Derecho penal español, Parte general, 18. a ed. (revisada y puesta al día por SERRANO GÓmEZ), Madrid.

SAlÀs Darrocha, J. T., 2004: «El maltrato de animales en el Código Penal: LO 15/03, de 25 de noviembre», en Sentencias de TSJ y AP y otros Tribunales num. 9/2004. Parte estudio, Pamplona, Aranzadi.

SEgrelles de ArenAZA, I., 2000: «Faltas contra los intereses generales», en CoBO DEL Rosal (coord.), Compendio de Derecho penal español. Parte especial, Madrid, Marcial Pons.

SuÁrez-Mira Rodríguez, C. (coord.), 2004: Manual de Derecho penal, t. II, Parte especial, Thomson-Civitas.

Tierno GalvÁn, E., 1987: Desde el espectáculo a la trivialización, Madrid, Tecnos.

Villalón, F., 1986: Taurofilia racial, Madrid, Ediciones El Observatorio.Vives AnTón, T. S. (coord.), 1996: Comentarios al Código Penal de 1995, vol. II, Valencia, Tirant lo Blanch. 